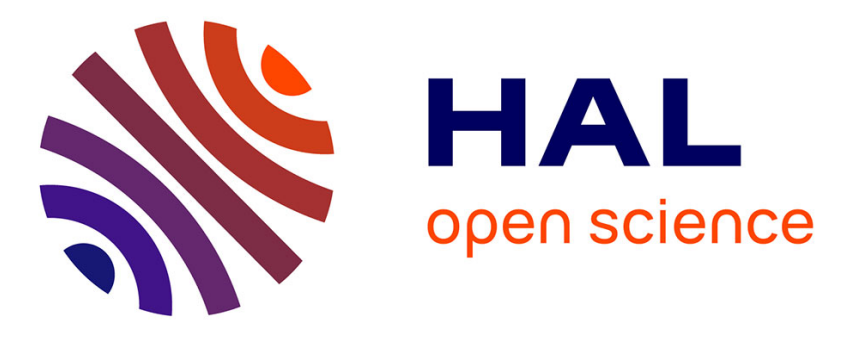

\title{
Kinetics of archived M184V mutation in treatment-experienced virally suppressed HIV-infected patients
}

Romain Palich, Elisa Teyssou, Sophie Sayon, Basma Abdi, Cathia Soulie, Lise Cuzin, Roland Tubiana, Marc-Antoine Valantin, Luminita Schneider, Sophie Seang, et al.

\section{To cite this version:}

Romain Palich, Elisa Teyssou, Sophie Sayon, Basma Abdi, Cathia Soulie, et al.. Kinetics of archived M184V mutation in treatment-experienced virally suppressed HIV-infected patients. Journal of Infectious Diseases, 2022, 10.1093/infdis/jiab413 . hal-03360134

\section{HAL Id: hal-03360134 \\ https://hal.sorbonne-universite.fr/hal-03360134}

Submitted on 30 Sep 2021

HAL is a multi-disciplinary open access archive for the deposit and dissemination of scientific research documents, whether they are published or not. The documents may come from teaching and research institutions in France or abroad, or from public or private research centers.
L'archive ouverte pluridisciplinaire HAL, est destinée au dépôt et à la diffusion de documents scientifiques de niveau recherche, publiés ou non, émanant des établissements d'enseignement et de recherche français ou étrangers, des laboratoires publics ou privés. 
Kinetics of archived M184V mutation in treatment-experienced virally suppressed HIV-infected patients

Romain Palich ${ }^{1,2^{*}}$, Elisa Teyssou², Sophie Sayon ${ }^{2}$, Basma Abdi², Cathia Soulie², Lise Cuzin ${ }^{3,4}$, Roland Tubiana ${ }^{1}$, Marc-Antoine Valantin ${ }^{1}$, Luminita Schneider ${ }^{1}$, Sophie Seang ${ }^{1}$, Marc Wirden ${ }^{2}$, Valérie Pourcher $^{1}$, Christine Katlama ${ }^{1}$, Vincent Calvez ${ }^{2}$, Anne-Geneviève Marcelin ${ }^{2}$

1. Sorbonne University, Infectious Diseases Department, Pitié-Salpêtrière Hospital, APHP, Pierre Louis Epidemiology and Public Health Institute (iPLESP), INSERM 1136, Paris, France

2. Sorbonne University, Virology Department, Pitié-Salpêtrière Hospital, AP-HP, Pierre Louis Epidemiology and Public Health Institute (iPLESP), INSERM 1136, Paris, France

3. CERPOP, Toulouse University, Inserm UMR1295, UPS, Toulouse, France

4. Martinique University Hospital, Infectious Diseases Department, 97200 Fort-deFrance, France 


\section{Corresponding author}

Romain Palich, MD

Service des Maladies Infectieuses, hôpital Pitié-Salpêtrière, 47-83 boulevard de l'hôpital, 75013 Paris

Tel: +33.1.42.16.01.71, fax: +33.1.42.16.04.45

Email: romain.palich@aphp.fr

\section{Summary of the article's main point}

Sequencing with ultrasensitive technique showed that the M184V mutation could be progressively cleared in the HIV-DNA reservoir over time, in virally suppressed HIV-patients. However, this mutation was likely to persist in patients with sustained past replication under lamivudine or emtricitabine. 


\section{ABSTRACT}

Background. We aimed to assess the kinetics of drug-resistant viral variants (DRVs) harboring the M184V mutation in the proviral DNA of long-term virally suppressed patients, and factors associated with DRV persistence.

Methods. HIV-DNA from blood cells stored in 2019 and 2016 was sequenced using both Sanger and ultradeep sequencing (SS and UDS, with a detection threshold of 1\%) in ART-treated patients with HIV-RNA $<50$ copies/mL for at least 5 years, with past M184V mutation documented in HIV-RNA.

Results. Among the 79 tested patients, by combining SS and UDS, the M184V was found to be absent in 26/79 (33\%) patients (M184V-patients), and persisted in 53/79 (67\%) (M184V+ patients). The M184V+ patients had a longer history of ART, a lower CD4 nadir and higher pretherapeutic HIVRNA. Among the 37 patients with viral sequences assessed by UDS, the proportion of M184V+ DRVs significantly decreased between 2016 and 2019 (40\% versus 14\%, p=0.005). The persistence of M184V was associated with the duration and level of HIV-RNA replication under 3TC/FTC $(p=0.0009$ and $p=0.009$, respectively).

Conclusion. While it decreased over time in HIV-DNA, the M184V mutation was more frequently persistent in the HIV-DNA of more experienced patients with longer past replication under 3TC/FTC.

\section{Keywords}

M184V; HIV; antiretroviral treatment; HIV reservoir; ultradeep sequencing 


\section{INTRODUCTION}

The M184V resistance-associated mutation (RAM) is selected by lamivudine (3TC) and emtricitabine (FTC), and induces high-level resistance to these two drugs [1]. M184V is rapidly selected in the setting of non-suppressive antiretroviral therapy (ART) and archived in the HIV reservoir [2]. As lamivudine continues to be used extensively as part of all recommended antiretroviral regimens, M184V is commonly found in patients with virological failure [3]. ART guidelines do not recommend the use of drugs impacted by RAMs as they have been shown to be a risk factor for virological failure $[4,5]$. Nevertheless, several studies have suggested that 3TC/FTC can retain activity even in the presence of $\mathrm{M} 184 \mathrm{~V}$ in the past [6-9].

Characterizing the viral resistance profile for each individual on ART is a key challenge for lifelong ART management. To detect archived RAMs, HIV-DNA resistance genotype tests can be performed on the blood cells of virally suppressed patients. As past RAMs, documented by RNA genotypes, have not been systematically found on DNA genotypes, researchers have concluded that DNA genotypes are less sensitive in detecting RAMs than cumulative RNA genotypes $[10,11]$. One could also argue that mutations may have been cleared, as suggested by recent works using ultradeep sequencing (UDS) $[12,13]$. Given the potential benefits of lamivudine in the ART armamentarium, we aimed to assess whether, after a long period of viral suppression, the M184V mutation present in the past in replicative HIV could be cleared in blood proviral DNA, using Sanger sequencing (SS) and UDS. We also aimed to determine the factors related to the persistence of this mutation. 


\section{MATERIAL AND METHODS}

\section{Study population}

For this observational study, we selected all HIV-1 infected patients in care at Pitié-Salpêtrière Hospital (Paris, France) in 2019, with an HIV-RNA viral load $<20$ copies/mL for at least 5 years, in whom the M184V mutation had been identified at least once in a previous RNA genotype resistance test.

Data collection

Patients' characteristics (gender, age, birth country) and HIV medical history (transmission factor, time since HIV diagnosis, CDC stage C, CD4 nadir, pretherapeutic HIV-RNA, HIV sub-type, ART duration, number and duration of previous ART regimens, and level of HIV-RNA replication while receiving 3TC/FTC, CD4 count and CD4/CD8 ratio, duration of viral suppression, ongoing $A R T)$ were collected at the time of the last available blood sample in 2019. Past HIV-RNA resistance genotypes were collected and reinterpreted using the latest version of the ANRS algorithm (www.hivfrenchressistance.org). 


\section{Study endpoints}

Study endpoints were: 1) the proportion of patients with viruses harboring the M184V mutation in proviral DNA from peripheral blood cells from the last sample available in 2019 , using SS, and 2) the proportion of M184V+ DRVs detected from blood cells in 2019 and 2016, using UDS (detection threshold: 1\%). RAMs in the reverse transcriptase gene, other than M184V, were identified from past HIV-RNA genotypes and assessed by SS on HIV-DNA from 2019, in order to assess whether there was a similar kinetics of the M184V mutation and the other RAMs over time.

Procedures

SS was performed only from all samples of 2019. UDS was performed from samples of 2019 and 2016, if the M184V was not detected by SS from samples of 2019. SS and UDS were performed from frozen whole blood samples according to the ANRS-MIE (French National Agency for Research on AIDS and Emerging Infectious Diseases) consensus using Illumina technology (Illumina, San Diego, California, USA), as previously described [14]. The sequence reads were analyzed with Geneious software v.2021.1.1. For UDS, the minimum coverage was set at 50 and the ambiguity filter at $1 \%$. Cell-associated HIV-1 DNA was quantified from frozen whole blood samples by ultrasensitive realtime PCR (Generic HIV-DNA assay, Biocentric, Bandol, France) as previously described [15].

All HIV-RNA values were quantified using the Cobas AmpliPrep/CobasTaqMan HIV-1 assay (Roche Diagnostics, RischRotkreuz, Switzerland) with a lower detection limit of 20 copies $/ \mathrm{mL}$. Ultra-sensitive viral load in the range of $1-20$ copies/ml was indicated qualitatively (presence or absence of a detectable signal) [16]. 


\section{Statistics}

All reported values are medians with interquartile range (IQR) for continuous variables and frequencies for categorical variables. We defined two groups of patients according to M184V mutation detection in HIV-DNA in 2019 using SS and UDS: the "M184V+" group (M184V detected by Sanger sequencing or as a DRV >1\% by UDS) and the "M184V-" group (M184V undetected by Sanger sequencing and UDS). Uni- and multivariable logistic regressions were used to analyze factors associated with M184V persistence. The multivariable model was constructed by step-by-step descending, initially including all characteristics related to M184V persistence and subsequently removing those with a p-value greater than 0.05 . We also assessed the potential correlation between the proportion of $\mathrm{M} 184 \mathrm{~V}+$ variants detected from samples of 2019 and the time from the last M184V detection in HIV-RNA, using a Pearson's test.

\section{Ethics}

All patients are routinely followed using the Nadis electronic medical record [17], and they provided signed consent ("French National Information Technology and Civil Liberties Board, CNIL" registration number: 770134) for information on record to be used. All data were anonymized before analysis. Patients were systematically notified of any supplementary biological analyses on frozen samples, initially collected as part of routine clinical practice. 


\section{RESULTS}

\section{Study population}

A total of 110 patients fulfilling the inclusion criteria were identified (Figure 1). The median time since detection of the M184V mutation in RNA genotypes was 9.1 years (IQR 8.1-11.1). The reverse transcriptase gene was successfully amplified from peripheral HIV-DNA in 79/110 (72\%) patients. Patients' characteristics are shown in Table 1. Their median duration on ART was 23.8 years (IQR 20.1-26.8) with a median viral suppression period of 8.9 years (IQR 6.8-10.7). Ongoing ART included 3TC/FTC in $39 \%$ of cases. Median level of total HIV-DNA was 3.44 copies $/ 10^{6}$ cells (IQR $3.10-3.70$ ).

\section{M184V detection by Sanger and ultradeep sequencing}

The M184V mutation was detected in HIV-DNA from blood cells in 53/79 (67\%) patients, including 42 using SS and 11 using UDS (Figure 1). In the remaining 26/79 (33\%) patients, the M184V mutation was not detected, either by SS or by UDS. In the 37 patients sampled by UDS from samples of 2019, M184V+ DRVs were detected in the range of $1-25 \%$. The proportion of patients with DRVs between $5-15 \%$ was $16 \%(6 / 37)$, and $\geq 15-25 \%$ was $14 \%(5 / 37)$. Of note, no patient had M184V+ DRVs between 1-5\%. Between 2016 and 2019, the proportion of viral variants carrying the M184V mutation decreased from $40 \%$ in 2016 to $14 \%$ in 2019 (mean difference: $-18.5 \%, 95 \% \mathrm{Cl}-31.0$ to -6.0 , $p=0.005$ ) (Figure 2). From samples of 2016, the proportion of patients with M184V+ DRVs $<1 \%$ was $56 \%(19 / 33)$, between $1-5 \%$ was $6 \%(2 / 33)$, between $5-15 \%$ was $0 \%(0 / 33)$ and $\geq 15-25 \%$ was $36 \%$ $(12 / 33)$. 
RAMs other than M184V were more frequently detected in cumulative past RNA genotypes, in comparison with recent DNA genotype, with 4 RAMs in median (IQR 2-6) detected in HIV-RNA and 2 (IQR 0-5) in HIV-DNA (mean difference: $-1.2,95 \% \mathrm{Cl}-2.0$ to $-0.3, \mathrm{p}=0.007$ ), using SS.

\section{Factors associated with M184V mutation persistence}

In univariate analysis, patients with persistent M184V mutation had a longer history of both HIV infection and ART, a lower CD4 nadir and higher pretherapeutic HIV-RNA (Table 2). The duration and level of plasma HIV-RNA replication under 3TC or FTC were higher in patients with persistent M184V mutation. Duration of viral suppression, quantification of total HIV-DNA in blood cells, composition of ART and proportion of patients with residual viremia did not differ between the two groups. There was a median difference of one RAM (except M184V) between cumulated HIV-RNA and HIVDNA genotypes in both groups.

In multivariable analysis, the duration of viral replication and the level of HIV-RNA while taking 3TC or FTC were significantly associated with persistence of the M184V mutation, with odds ratios of 1.03 per month of replication $(95 \% \mathrm{Cl} 1.02$ to $1.05, \mathrm{p}=0.0009)$ and 3.17 per $\log _{10}$ copies $/ \mathrm{mL}(95 \% \mathrm{Cl}$ 1.61 to $7.02, p=0.009$ ), respectively (Table 2 ).

There was no correlation between the proportion of M184V+ variants detected from samples of 2019 and the time from the last M184V detection in HIV-RNA ( $\rho=0.04,95 \% \mathrm{Cl}-0.29$ to $+0.36, p=0.81)$. 


\section{DISCUSSION}

Given the importance of lamivudine and emtricitabine in all current antiretroviral strategies, determining whether M184V persists in the HIV reservoir in long-term virally suppressed patients is key for the choice of best therapeutic options. In this study, we found that while the M184V mutation persisted in $67 \%$ of tested patients over 5 years, clearance of the mutation was observed in $33 \%$ of patients. This high rate of $\mathrm{M} 184 \mathrm{~V}$ persistence can be partially explained by the restrictive definition of persistence, using a detection threshold of $1 \%$. UDS allowed the proportion of detected M184V mutations to rise in a substantial number of patients, as previously described, whereas SS failed to detect viral variants present in less than $15-25 \%$ of the total viral population $[18,19]$.

The relevance of detecting DRVs for predicting virological failure is controversial [20]. It has been shown to be clinically meaningful in three settings: detection of NNRTI-resistant minority variants prior to initiation of a first-line NNRTI-based regimen [21], detection of NNRTI-resistant minority variants after exposure to a single dose of nevirapine [22] and detection of CXCR4-using variants prior to initiation of maraviroc-containing regimens [23], with debated thresholds for detection (15\%). The data in the literature are not all convergent concerning the most suitable threshold for detecting DRVs with UDS. The risk in lowering this threshold is to reflect sequencing errors. However, several authors have shown that a detection threshold of $1 \%$ was relevant to improve the sensitivity of genotyping $[24,25]$, which explains our choice for this work. We did not find any patient with M184V+ DRVs between 1-5\% from samples we studied. Therefore, choosing a detection threshold of $5 \%$ would not have changed the result of our analysis.

Previous works have suggested poor sensitivity of Sanger sequencing for detecting archived RAMs in blood proviral DNA in comparison with past RNA genotypes $[10,11]$. Two main hypothesizes could explain the lack of sensitivity of DNA genotyping: difficulty extracting and amplifying the genetic 
material from whole blood with the risk of selecting a small part of the circulating reservoir, and insufficient capture of resistant archived variants, potentially diluted into a large library of viral variants, integrated in the mononuclear cells and including a majority of wild type variants. Consequently, it has been suggested that DNA genotype testing be performed in duplicate or triplicate, which has its limitations, however, in terms of feasibility and costs. Like others, we assume that UDS can improve the sensitivity of standard DNA genotyping [26], although limited selection of amplified archived variants cannot be excluded.

Sustained quantitative and qualitative alterations occurred in virally suppressed patients. Total HIVDNA from blood, used as a surrogate for the HIV reservoir [27], sharply decreases in the first years on ART, and then much more slowly but continuously $[28,29]$. A recent study showed that intact proviral DNA (i.e. competent for replication) continues to decline between 7 and 11 years after ART initiation in virally suppressed patients [30]. Furthermore, different genetic mechanisms impairing the integrity of proviral DNA, including inversions, large deletions and hypermutations $G$ to $A$ by the APOBEC pathway, have been reported [29]. It is estimated that intact proviral DNA constitutes $<10 \%$ of total proviral DNA in chronic virally suppressed patients on ART [31-33].

Despite the presence of long-lived HIV-infected lymphocytes potentially harboring viral mutations and their maintenance due to persistent very low-level replication [34-37], recent data argue for real clearance of RAMs in proviral DNA. In a pilot study, Nouchi et al. showed a progressive decrease in the proportion of NRTI- and NNRTI-resistant minority variants over five years [12] in patients virally suppressed for at least 5 years, on non NRTI or NNRTI-containing ART regimens. In patients with significant virological failures in the past, Gantner, et al. reported that NRTI-, NNRTI- and PIresistant minority variants were no longer detected in PBMC over time if the ART regimen excluded these drugs [13]. Our study supports the progressive decrease in the M184V mutation over time, with a kinetic not affected by the therapeutic pressure of 3TC/FTC. Eleven out of $26(42 \%)$ patients with cleared $\mathrm{M} 184 \mathrm{~V}$ were receiving $3 \mathrm{TC} / \mathrm{FTC}$ at the time of analysis. One of the unresolved questions 
is the impact of persistent RAMs, given that they are carried by a large majority of defective proviruses.

In addition to this finding on the clearance of RAMs, we found two factors - the duration of viral replication on 3TC/FTC and the level of replicative HIV-RNA - to be associated with M184V mutation persistence. This suggests that sustained seeding of the HIV reservoir with proviruses carrying RAMs leads to sustained persistence of RAMs over time, which corroborates data from Verhofstede, et al [38]. In this study, the proportion of resistant variants was correlated with the duration for which resistant variants had been able to replicate. Interestingly, we did not find any impact of either residual viremia or level of blood total HIV-DNA viral load, even though our patients had higher total HIV-DNA than in other studies $[25,39]$, which may be due to long and deep seeding of the HIV reservoir in these patients treated over 20 years. Aging patients with a long HIV history are those who could benefit the most from drug-reduced ART, in terms of preventing drug-drug interactions and long-term cumulative toxicities [40]. Unfortunately, these are the patients in whom the M184V mutation could persist the longest.

One limitation of our work is the fact that we did not evaluate the non-circulating HIV reservoir, including the lymph nodes and gut. Although total blood HIV-DNA could reflect the overall level of the HIV reservoir [27], genetic evolution of viral sequences could be dissociated in these different compartments [36]. The study of the extra-circulating reservoir requires invasive techniques that are very difficult to implement in clinical practice. Another limitation could be not having performed UDS in patients who harbored the M184V using SS. We assumed that M184V would also be detected in UDS, which however we did not verify. We did not evaluate APOBEC editing and hypermutations from UDS data, because we amplified only a small segment of the RT gene, on either side of the position 184, not allowing this to be analyzed on a sufficient portion of HIV-DNA.

Better knowledge of the profile of patients with M184V clearance could make it possible to select candidates for clinical trials assessing the efficacy of antiretroviral regimens including 3TC, despite 
previous virological failures under NRTIs. This question is crucial for dual therapies including 3TC, to accompany boosted darunavir or dolutegravir. The MOBIDIP study and its associated in-depth virological analysis suggested that an archived M184V mutation may not affect the viral efficacy of the darunavir/ritonavir/lamivudine two-drug therapy $[6,41]$. However, data are much less robust for the dolutegravir/lamivudine two-drug therapy, with a very limited number of patients included $[8,9,42]$.

In conclusion, our findings provide new data on the persistence and progressive clearance of the M184V mutation in the HIV reservoir. Recycling drugs with viral activity potentially impaired by past resistance is now a key challenge in ART management. Assessing the benefit of proviral DNA genotyping in a randomized trial could provide a robust answer to this question. 
FOOTNOTE PAGE

\section{Funding}

This study was supported by ViiV Healthcare and the ANRS-MIE, AC43 (French National Agency for Research on AIDS and Emerging Infectious Diseases).

\section{Transparency declaration}

$\mathrm{RP}, \mathrm{BA}, \mathrm{CS}, \mathrm{LC}, \mathrm{RT}, \mathrm{MAV}, \mathrm{LS}, \mathrm{SS}, \mathrm{MW}, \mathrm{VP}, \mathrm{CK}, \mathrm{VC}$ and $\mathrm{AGM}$ have received travel grants and honoraria from Gilead, ViiV Healthcare, Janssen and Merck. ET and SS have no conflict of interest to declare. 


\section{REFERENCES}

1. Turner D, Brenner B, Wainberg MA. Multiple effects of the M184V resistance mutation in the reverse transcriptase of human immunodeficiency virus type 1. Clin Diagn Lab Immunol, 2003; 10:979-981.

2. Lambotte O, Chaix M-L, Gubler B, et al. The lymphocyte HIV reservoir in patients on longterm HAART is a memory of virus evolution. AIDS, 2004; 18:1147-1158.

3. Schuurman R, Nijhuis M, van Leeuwen R, et al. Rapid changes in human immunodeficiency virus type 1 RNA load and appearance of drug-resistant virus populations in persons treated with lamivudine (3TC). J Infect Dis, 1995; 171:1411-1419.

4. Delaugerre C, Valantin MA, Mouroux M, et al. Re-occurrence of HIV-1 drug mutations after treatment re-initiation following interruption in patients with multiple treatment failure. AIDS, 2001; 15:2189-2191.

5. Devereux HL, Loveday C, Youle M, Sabin CA, Burke A, Johnson MA. Reduction in human immunodeficiency virus type 1 mutations associated with drug resistance after initiating new therapeutic regimens in pretreated patients. J Infect Dis, 2000; 181:1804-1807.

6. Ciaffi L, Koulla-Shiro S, Sawadogo AB, et al. Boosted protease inhibitor monotherapy versus boosted protease inhibitor plus lamivudine dual therapy as second-line maintenance treatment for HIV-1-infected patients in sub-Saharan Africa (ANRS12 286/MOBIDIP): a multicentre, randomised, parallel, open-label, superiority trial. Lancet HIV, 2017; 4:e384-e392.

7. Olearo F, Nguyen $\mathrm{H}$, Bonnet F, et al. Impact of the M184V/I Mutation on the Efficacy of Abacavir/Lamivudine/Dolutegravir Therapy in HIV Treatment-Experienced Patients. Open Forum Infect Dis, 2019; 6:ofz330.

8. Gagliardini R, Ciccullo A, Borghetti A, et al. Impact of the M184V Resistance Mutation on 
Virological Efficacy and Durability of Lamivudine-Based Dual Antiretroviral Regimens as Maintenance Therapy in Individuals With Suppressed HIV-1 RNA: A Cohort Study. Open Forum Infect Dis, 2018; 5:ofy113.

9. Rial-Crestelo D, de Miguel R, Montejano R, et al. Long-term efficacy of dolutegravir plus lamivudine for maintenance of HIV viral suppression in adults with and without historical resistance to lamivudine: Week 96 results of ART-PRO pilot study. J Antimicrob Chemother, 2020; dkaa479.

10. Delaugerre C, Braun J, Charreau I, et al. Comparison of resistance mutation patterns in historical plasma HIV RNA genotypes with those in current proviral HIV DNA genotypes among extensively treated patients with suppressed replication. HIV Med, 2012; 13:517-525.

11. Wirden M, Soulie C, Valantin M-A, et al. Historical HIV-RNA resistance test results are more informative than proviral DNA genotyping in cases of suppressed or residual viraemia. J Antimicrob Chemother, 2011; 66:709-712.

12. Nouchi A, Nguyen T, Valantin MA, et al. Dynamics of drug resistance-associated mutations in HIV-1 DNA reverse transcriptase sequence during effective ART. J Antimicrob Chemother, 2018; 73:2141-2146.

13. Gantner $\mathrm{P}$, Morand-Joubert $\mathrm{L}$, Sueur $\mathrm{C}$, et al. Drug resistance and tropism as markers of the dynamics of HIV-1 DNA quasispecies in blood cells of heavily pretreated patients who achieved sustained virological suppression. J Antimicrob Chemother, 2016; 71:751-761.

14. Lapointe HR, Dong W, Lee GQ, et al. HIV drug resistance testing by high-multiplex 'wide' sequencing on the MiSeq instrument. Antimicrob Agents Chemother, 2015; 59:6824-6833.

15. Avettand-Fènoël V, Chaix M-L, Blanche S, et al. LTR real-time PCR for HIV-1 DNA quantitation in blood cells for early diagnosis in infants born to seropositive mothers treated in HAART area (ANRS CO 01). J Med Virol, 2009; 81:217-223. 
16. Lambert-Niclot S, Grude M, Meynard J-L, et al. Ultrasensitive Human Immunodeficiency Virus Type 1 Viral Load as a Marker of Treatment Choice for Simplification Strategies. Clin Infect Dis, 2018; 67:1883-1889.

17. Pugliese $P$, Cuzin L, Cabié A, et al. A large French prospective cohort of HIV-infected patients: the Nadis Cohort. HIV Med, 2009; 10:504-511.

18. Tzou PL, Ariyaratne $\mathrm{P}$, Varghese $\mathrm{V}$, et al. Comparison of an In Vitro Diagnostic NextGeneration Sequencing Assay with Sanger Sequencing for HIV-1 Genotypic Resistance Testing. J Clin Microbiol, 2018; 56(6):e00105-18.

19. Ávila-Ríos S, Parkin N, Swanstrom R, et al. Next-Generation Sequencing for HIV Drug Resistance Testing: Laboratory, Clinical, and Implementation Considerations. Viruses, 2020; 12(6):617.

20. Stella-Ascariz N, Arribas JR, Paredes R, Li JZ. The Role of HIV-1 Drug-Resistant Minority Variants in Treatment Failure. J Infect Dis, 2017; 216:S847-S850.

21. Li JZ, Paredes R, Ribaudo HJ, et al. Low-frequency HIV-1 drug resistance mutations and risk of NNRTI-based antiretroviral treatment failure: a systematic review and pooled analysis. JAMA, 2011; 305:1327-1335.

22. Boltz VF, Zheng $\mathrm{Y}$, Lockman $\mathrm{S}$, et al. Role of low-frequency HIV-1 variants in failure of nevirapine-containing antiviral therapy in women previously exposed to single-dose nevirapine. Proc Natl Acad Sci, 2011; 108:9202-9207.

23. Kagan RM, Johnson EP, Siaw M, et al. A genotypic test for HIV-1 tropism combining Sanger sequencing with ultradeep sequencing predicts virologic response in treatment-experienced patients. PloS One, 2012; 7:e46334.

24. Mohamed S, Penaranda G, Gonzalez D, et al. Comparison of ultra-deep versus Sanger 
sequencing detection of minority mutations on the HIV-1 drug resistance interpretations after virological failure. AIDS, 2014; 28(9):1315-1324.

25. Rodriguez C, Nere ML, Demontant V, et al. Ultra-deep sequencing improves the detection of drug resistance in cellular DNA from HIV-infected patients on ART with suppressed viraemia. J Antimicrob Chemother, 2018; 73(11):3122-3128.

26. Alidjinou EK, Coulon P, Hallaert C, et al. Routine drug resistance testing in HIV-1 proviral DNA, using an automated next- generation sequencing assay. J Clin Virol, 2019; 121:104207.

27. Avettand-Fènoël V, Hocqueloux L, Ghosn J, et al. Total HIV-1 DNA, a Marker of Viral Reservoir Dynamics with Clinical Implications. Clin Microbiol Rev, 2016; 29:859-880.

28. Golob JL, Stern J, Holte S, et al. HIV DNA levels and decay in a cohort of 111 long-term virally suppressed patients. AIDS, 2018; 32:2113-2118.

29. Bachmann N, von Siebenthal C, Vongrad V, et al. Determinants of HIV-1 reservoir size and long-term dynamics during suppressive ART. Nat Commun, 2019; 10:3193.

30. Gandhi R, Cyktor J, Bosch R, et al. Intact proviral DNA levels decline in people with HIV on antiretroviral therapy [Abstract 75]. Boston, USA, $27^{\text {th }}$ Conference on Retroviruses and Opportunistic Infections (CROI), 2020.

31. Bruner KM, Murray AJ, Pollack RA, et al. Defective proviruses rapidly accumulate during acute HIV-1 infection. Nat Med, 2016; 22:1043-1049.

32. Imamichi H, Dewar RL, Adelsberger JW, et al. Defective HIV-1 proviruses produce novel protein-coding RNA species in HIV-infected patients on combination antiretroviral therapy. Proc Natl Acad Sci, 2016; 113:8783-8788.

33. Ho Y-C, Shan L, Hosmane NN, et al. Replication-competent noninduced proviruses in the latent reservoir increase barrier to HIV-1 cure. Cell, 2013; 155:540-551. 
34. Siliciano JD, Kajdas J, Finzi D, et al. Long-term follow-up studies confirm the stability of the latent reservoir for HIV-1 in resting CD4+ T cells. Nat Med, 2003; 9:727-728.

35. Chomont N, El-Far M, Ancuta $\mathrm{P}$, et al. HIV reservoir size and persistence are driven by $\mathrm{T}$ cell survival and homeostatic proliferation. Nat Med, 2009; 15:893-900.

36. Lorenzo-Redondo R, Fryer HR, Bedford T, et al. Persistent HIV-1 replication maintains the tissue reservoir during therapy. Nature, 2016; 530:51-56.

37. Palmer S, Maldarelli F, Wiegand A, et al. Low-level viremia persists for at least 7 years in patients on suppressive antiretroviral therapy. Proc Natl Acad Sci, 2008; 105:3879-3884.

38. Verhofstede C, Noë A, Demecheleer E, et al. Drug-resistant variants that evolve during nonsuppressive therapy persist in HIV-1-infected peripheral blood mononuclear cells after long-term highly active antiretroviral therapy. J Acquir Immune Defic Syndr, 2004; 35:473-483.

39. Cuzin L, Pugliese P, Sauné K, et al. Levels of intracellular HIV-DNA in patients with suppressive antiretroviral therapy. AIDS, 2015; 29:1665-1671.

40. Katlama C, Ghosn J, Murphy RL. Individualized antiretroviral therapeutic approaches: less can be more. AIDS, 2017; 31:1065-1071.

41. Delaugerre C, Nere M-L, Eymard-Duvernay S, et al. Deep sequencing analysis of M184V/I mutation at the switch and at the time of virological failure of boosted protease inhibitor plus lamivudine or boosted protease inhibitor maintenance strategy (substudy of the ANRS-MOBIDIP trial). J Antimicrob Chemother, 2021; 76(5):1286-1293.

42. Reynes J, Montes B, Tuaillon E, Meftah N, Fernandez C. Virological efficacy and tolerability of dual therapy maintenance with dolutegravir plus lamivudine in heavily treatment experienced HIVinfected patients: Four years data from DOLULAM study [Abstract PEB0241]. San Francisco, USA, 23 ${ }^{\text {rd }}$ AIDS International Conference, 2020. 
Table 1. Patients' characteristics.

\begin{tabular}{|c|c|c|c|c|}
\hline & & All patients $(n=79)$ & M184V- $(n=26)$ & $M 184 V+(n=53)$ \\
\hline Gender, n(\%) & Male & $62(79)$ & $21(81)$ & $41(77)$ \\
\hline Age, years, median (IQR) & & $57(52-63)$ & $57(50-68)$ & $57(53-63)$ \\
\hline \multirow[t]{3}{*}{ Risk factor, $\mathrm{n}(\%)$} & MSM & $41(52)$ & $9(35)$ & $32(60)$ \\
\hline & Heterosexual & $24(30)$ & $13(50)$ & $11(21)$ \\
\hline & Other & $14(18)$ & $4(15)$ & $10(19)$ \\
\hline \multirow[t]{3}{*}{ Birth country, $n(\%)$} & France & $48(61)$ & $12(46)$ & $36(68)$ \\
\hline & Sub-Saharan Africa & $18(23)$ & $8(31)$ & $10(19)$ \\
\hline & Other & $13(16)$ & $6(23)$ & $7(13)$ \\
\hline Time from HIV diagnosis, years, median (IQR) & & $27.0(22.9-30.3)$ & $23.7(17.8-27.7)$ & $27.9(24.2-30.6)$ \\
\hline
\end{tabular}




\begin{tabular}{|c|c|c|c|}
\hline CDC stage $\mathrm{C}, \mathrm{n}(\%)$ & $33(42)$ & $9(35)$ & $24(45)$ \\
\hline CD4 nadir, cells $/ \mathrm{mm}^{3}$, median (IQR) & $133(47-257)$ & $228(131-281)$ & $86(30-206)$ \\
\hline Pretherapeutic HIV-RNA, $\log _{10} \mathrm{cp} / \mathrm{mL}$, median (IQR) & $5.12(4.26-5.52)$ & $4.69(3.90-5.12)$ & $5.29(4.71-5.68)$ \\
\hline HIV sub-type, n(\%) & $58(73)$ & $16(62)$ & $42(79)$ \\
\hline Not B & $21(27)$ & $10(38)$ & $11(21)$ \\
\hline Time on ART, years, median (IQR) & $23.8(20.1-26.8)$ & $21.5(15.8-24.4)$ & $24.5(22.2-27.4)$ \\
\hline Previous number of ART regimens, median (IQR) & $13(9-18)$ & $11(8-14)$ & $15(10-20)$ \\
\hline Duration of viral replication under 3TC/FTC, years, median (IQR) & $5.6(2.7-7.9)$ & $2.7(1.1-5.4)$ & $6.6(3.7-8.6)$ \\
\hline Mean HIV-RNA during viral replication under $3 \mathrm{TC} / \mathrm{FTC}, \log _{10} \mathrm{cp} / \mathrm{mL}$, median $(\mathrm{IQR})^{\mathrm{b}}$ & $3.92(3.26-4.44)$ & $3.30(2.82-4.06)$ & $4.12(3.70-4.62)$ \\
\hline
\end{tabular}




\begin{tabular}{|c|c|c|c|c|}
\hline Last CD4, cells $/ \mathrm{mm}^{3}$, median (IQR) & & $614(453-866)$ & $623(503-866)$ & $592(380-877)$ \\
\hline Last $\mathrm{CD} 4 / \mathrm{CD} 8$ ratio, median (IQR) & & $0.90(0.56-1.18)$ & $0.83(0.65-1.23)$ & $0.94(0.56-1.19)$ \\
\hline Duration of viral suppression & & $8.9(6.8-10.7)$ & $8.4(6.0-10.0)$ & $9.0(7.3-10.9)$ \\
\hline HIV-RNA $<50 \mathrm{cp} / \mathrm{mL}$ but detectable by RT-PCR, $\mathrm{n}(\%)$ & & $26(33)$ & $8(31)$ & $18(34)$ \\
\hline HIV-DNA, $\log _{10} \mathrm{cp} / 10^{6}$ cells, median (IQR) & & $3.44(3.10-3.70)$ & $3.40(2.90-3.70)$ & $3.49(3.15-3.70)$ \\
\hline \multirow[t]{4}{*}{ Number of drugs in ongoing ART, $n(\%)$} & 1 & $7(9)$ & $3(12)$ & $4(8)$ \\
\hline & 2 & $35(44)$ & $11(42)$ & $24(45)$ \\
\hline & 3 & $33(42)$ & $11(42)$ & $22(41)$ \\
\hline & 4 & $4(5)$ & $1(4)$ & $3(6)$ \\
\hline 3TC/FTC as part of ongoing ART, $n(\%)$ & & $31(39)$ & $11(42)$ & $20(38)$ \\
\hline
\end{tabular}


NOTES. a. This duration was calculated by reviewing each medical record, by analyzing each available HIV-RNA value with the date of each value, as the sum of the times during which HIV-RNA was $\geq 200$ copies/mL under $3 T C / F T C$. b. This mean value was calculated by reviewing each medical record, by analyzing each available HIV-RNA value with the date of each value, as the mean of HIV-RNA values $\geq 200$ copies/mL under $3 T C / F T C$. MSM, men who have sex with men. 
Table 2. Uni and multi-variable logistic regression of patients' characteristics in relation to the presence of M184V in 2019.

\begin{tabular}{|c|c|c|c|c|c|}
\hline & & \multicolumn{2}{|c|}{ Univariable } & \multicolumn{2}{|c|}{ Multivariable } \\
\hline & & OR $(95 \% \mathrm{Cl})$ & p-value & OR $(95 \% \mathrm{Cl})$ & $p$-value \\
\hline \multirow[t]{2}{*}{ Gender } & Male & Ref & & & \\
\hline & Female & $0.46(0.18-1.67)$ & 0.17 & & \\
\hline \multirow[t]{4}{*}{ Age (by quartiles) } & $\leq 52$ years & Ref & & & \\
\hline & $53-57$ years & $2.40(0.80-7.61)$ & 0.19 & & \\
\hline & $58-63$ years & $2.62(0.83-9.10)$ & 0.18 & & \\
\hline & $>63$ years & $1.03(0.36-2.98)$ & 0.96 & & \\
\hline \multirow[t]{3}{*}{ Transmission } & MSM & Ref & & Ref & \\
\hline & Heterosexual & $0.24(0.09-0.58)$ & 0.01 & $0.38(0.11-1.23)$ & 0.18 \\
\hline & Other & $0.70(0.23-2.36)$ & 0.61 & $0.54(0.09-3.32)$ & 0.56 \\
\hline \multirow[t]{3}{*}{ Birth Country } & France & Ref & & Ref & \\
\hline & Sub-Saharan Africa & $0.42(0.16-1.09)$ & 0.08 & $1.56(0.25-11.31)$ & 0.69 \\
\hline & Other & $0.39(0.13-1.14)$ & 0.13 & $0.27(0.05-1.39)$ & 0.19 \\
\hline Time from HIV diagnosis (by quartiles) & $\leq 23$ years & Ref & & Ref & \\
\hline
\end{tabular}




\begin{tabular}{|c|c|c|c|c|c|}
\hline & 24-27 years & $2.78(0.97-8.43)$ & 0.11 & $0.03(0.0004-0.76)$ & 0.11 \\
\hline & $28-30$ years & $8.00(2.39-32.1)$ & 0.007 & $0.58(0.017-14.45)$ & 0.78 \\
\hline & $>30$ years & $6.00(1.92-21.14)$ & 0.013 & $0.19(0.006-4.96)$ & 0.41 \\
\hline \multirow[t]{2}{*}{ CDC Stage C } & No & Ref & & & \\
\hline & Yes & $1.56(0.70-3.61)$ & 0.37 & & \\
\hline \multirow[t]{2}{*}{ CD4 cells nadir } & $<200$ cells $/ \mathrm{mm}^{3}$ & Ref & & Ref & \\
\hline & $\geq 200$ cells $/ \mathrm{mm}^{3}$ & $0.26(0.11-0.60)$ & 0.008 & $0.36(0.11-1.07)$ & 0.13 \\
\hline \multirow[t]{2}{*}{ Pretherapeutic HIV-RNA } & $<5 \log _{10}$ copies $/ \mathrm{mL}$ & Ref & & Ref & \\
\hline & $\geq 5 \log _{10}$ copies $/ \mathrm{mL}$ & $2.47(1.11-5.61)$ & 0.06 & $1.20(0.37-3.80)$ & 0.80 \\
\hline \multirow[t]{2}{*}{ HIV Subtype } & B & Ref & & & \\
\hline & Not B & $0.42(0.17-1.00)$ & 0.10 & & \\
\hline \multirow[t]{4}{*}{ Time on ART (by quartiles) } & $\leq 21$ years & Ref & & Ref & \\
\hline & 22-24 years & 3.5 (1.19-10.93) & 0.06 & $7.18(1.16-58.65)$ & 0.09 \\
\hline & $25-27$ years & $4.2(1.39-13.81)$ & 0.04 & $2.63(0.42-16.96)$ & 0.38 \\
\hline & $>27$ years & $8.5(2.55-33.97)$ & 0.006 & $0.89(0.09-8.63)$ & 0.94 \\
\hline Number of previous ART regimens & (for one additional) & $1.12(1.05-1.22)$ & 0.01 & $0.99(0.88-1.16)$ & 0.98 \\
\hline Duration of viral replication under 3TC/FTC & (for one year) & $1.54(1.29-1.89)$ & 0.0001 & & \\
\hline Duration of viral replication under 3TC/FTC & (for one month) & $1.04(1.02-1.05)$ & 0.0001 & $1.03(1.02-1.05)$ & 0.0009 \\
\hline
\end{tabular}




\begin{tabular}{|c|c|c|c|c|c|}
\hline Mean HIV-RNA during viral replication under 3TC/FTC & (for $1 \log _{10}$ copies $/ \mathrm{mL}$ ) & $3.92(2.08-8.19)$ & 0.0009 & $3.17(1.61-7.02)$ & 0.009 \\
\hline \multirow[t]{4}{*}{ Last CD4, by quartiles } & $\leq 460$ cells $/ \mathrm{mm}^{3}$ & Ref & & & \\
\hline & $461-614$ cells $/ \mathrm{mm}^{3}$ & $0.18(2.24-18.5)$ & 0.024 & & \\
\hline & $615-860$ cells $/ \mathrm{mm}^{3}$ & $0.38(0.09-1.37)$ & 0.23 & & \\
\hline & $>860$ cells $/ \mathrm{mm}^{3}$ & $0.33(0.08-1.13)$ & 0.15 & & \\
\hline Last $\mathrm{CD} 4 / \mathrm{CD} 8$ ratio $>1$ & & $1.04(0.47-2.34)$ & 0.93 & & \\
\hline Duration of viral suppression & (for one year) & $1.12(0.98-1.30)$ & 0.18 & & \\
\hline HIV-RNA $<50 \mathrm{cp} / \mathrm{mL}$ but detectable by RT-PCR & & $1.16(0.50-2.76)$ & 0.78 & & \\
\hline HIV-DNA, $\log 10 \mathrm{cp} / 10^{6}$ cells & (for $1 \log _{10}$ copies $/ \mathrm{mL}$ ) & $1.22(0.61-2.41)$ & 0.63 & & \\
\hline \multirow[t]{4}{*}{ Number of drugs in ongoing ART, $n(\%)$} & 1 & Ref & & & \\
\hline & 2 & $1.63(0.38-6.60)$ & 0.56 & & \\
\hline & 3 & $1.50(0.35-6.07)$ & 0.63 & & \\
\hline & 4 & $2.25(0.26-31.27)$ & 0.56 & & \\
\hline 3TC/FTC as part of ongoing ART & & $0.85(0.38-1.92)$ & 0.74 & & \\
\hline Intermittent ART & & $0.97(0.37-2.79)$ & 0.96 & & \\
\hline
\end{tabular}

NOTES. MSM, men who have sex with men. 
Figure 1. Study flowchart.

Figure 2. Proportion of drug-resistant viral variants (DRVs) carrying the M184V mutation in blood HIV-DNA in 2016 and 2019. Each line represents one patient. *Student paired t-test. 
HIV-1 infected patients with past M184V (HIV-RNA genotype)

Plasma HIV-RNA $<50$ copies/mL for at least 5 years

Available frozen blood sample

$$
\mathbf{n}=110
$$

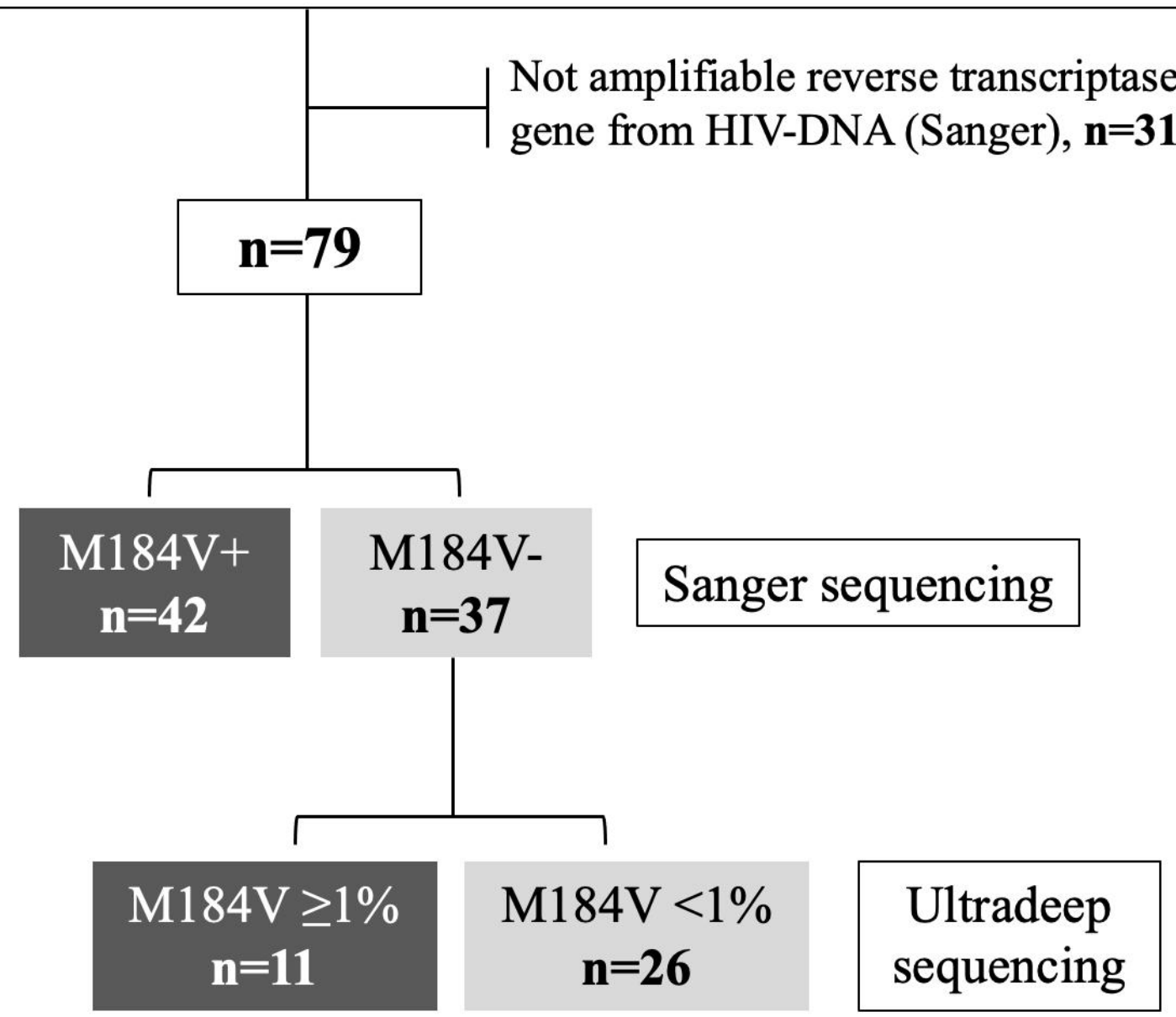


Figure 2

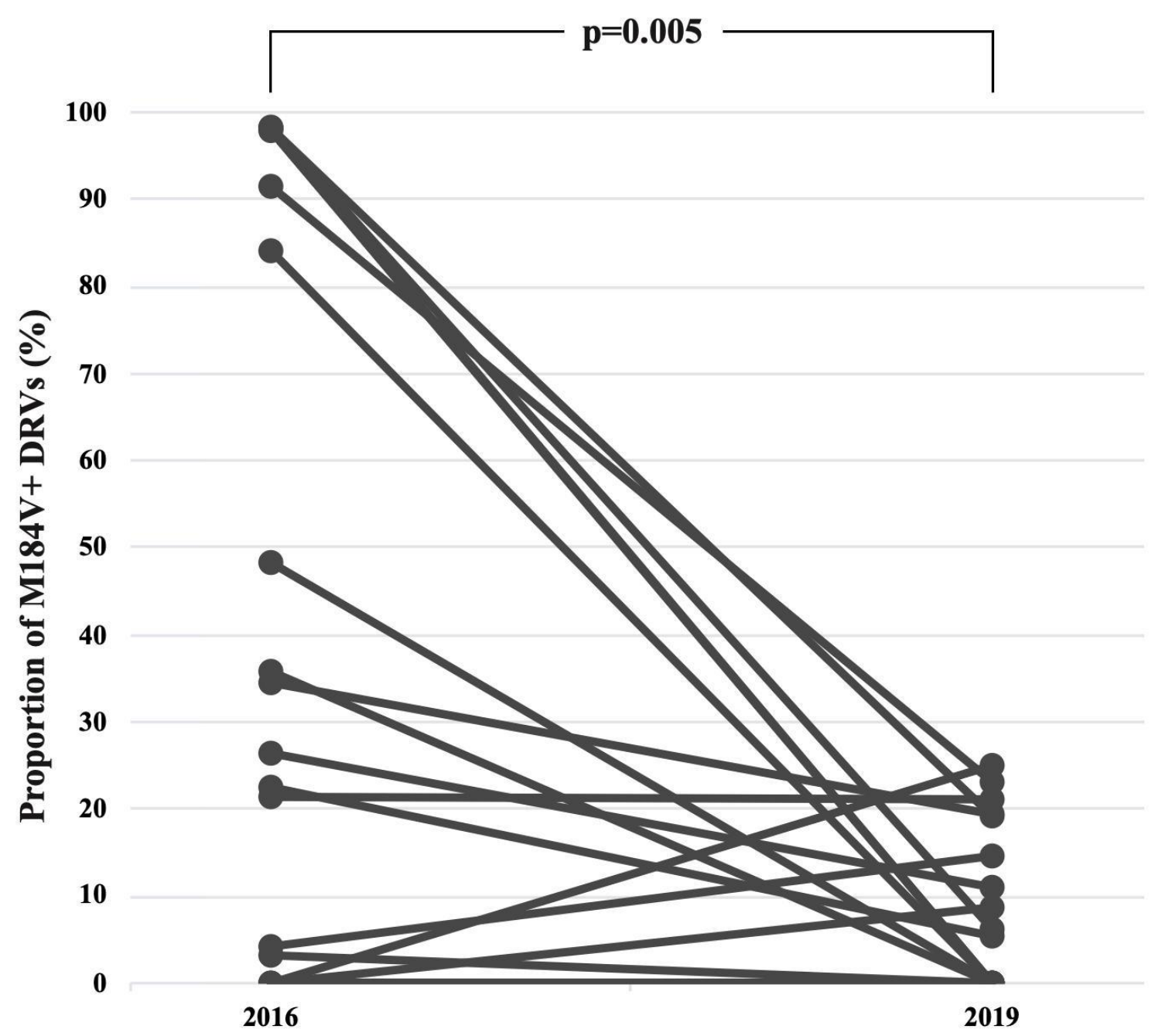

